NOTE

\title{
Estimating carrying capacity at the green turtle nesting beach of East Island, French Frigate Shoals
}

\author{
Manjula Tiwari $^{1, *}$, George H. Balazs ${ }^{2}$, Stacy Hargrove ${ }^{2}$ \\ ${ }^{1}$ Marine Turtle Ecology and Assessment Program, Protected Resources Division, Southwest Fisheries Science Center, \\ NOAA-National Marine Fisheries Service, La Jolla, California 92037, USA \\ ${ }^{2}$ Marine Turtle Research Program, Pacific Islands Fisheries Science Center, NOAA-National Marine Fisheries Service, \\ Honolulu, Hawaii 96822, USA
}

\begin{abstract}
Many sea turtle populations are at a fraction of their historical abundance, and understanding ecological processes, under current and climate change scenarios, is critical for establishing recovery goals. In the Hawaiian Islands, the nesting population of the green turtle Chelonia mydas on East Island, French Frigate Shoals, has been recovering at a rate of $5.7 \%$ per year. Climate change models, however, predict a loss in nesting habitat on East Island of up to $30 \%$ due to sea level rise by 2100. Therefore, the objective of the present study was to determine the carrying capacity of East Island for hatchlings and nesting females under current conditions and predictions of sea level rise. In the simulation model, density-dependent nest destruction was the primary factor regulating population size. Carrying capacity was reached between 1.9 and 2.1 million hatchlings at current conditions; carrying capacity was approached when 80000 to 120000 nests were laid on the beach, representing 20000 to 30000 nesting females. With a rise in sea level, carrying capacity was reached when 60000 to 100000 nests were laid on the beach. The current mean estimate of 390 nesting females per year, over the past $10 \mathrm{yr}$, at East Island represents 1.3 to $2 \%$ of the females that would nest at carrying capacity. The beach at East Island is well below carrying capacity and is capable of supporting a larger nesting population. However, the availability of suitable coastal habitats may play a bigger role in regulating the Hawaiian green turtle population than available nesting habitat.
\end{abstract}

KEY WORDS: Carrying capacity · Green turtles · Chelonia mydas · Nesting • Climate change · French Frigate Shoals · Hawaii

Resale or republication not permitted without written consent of the publisher

\section{INTRODUCTION}

Populations of green sea turtles Chelonia mydas have declined worldwide, and many populations are considered to be at a fraction of their historical abundance and environmental carrying capacity (Jackson et al. 2001, Seminoff 2004, Tiwari et al. 2006). However, recent analyses of global trends in green turtle nesting populations demonstrated a promising, and sometimes remarkable, increase over the past decades at several nesting rookeries (Bjorndal et al. 1999, Seminoff 2004, Troëng \& Rankin 2005, Broderick et al. 2006, Chaloupka et al. 2008). Among the rookeries that have responded positively to long-term protection is the green turtle population on East Island in French Frigate Shoals (Balazs 1976), which lie within the remote Northwestern Hawaiian Islands (Fig. 1), an area designated as the Papahanaumokuakea Marine National Monument in 2007. Prior to the mid 20th century, green turtles were heavily exploited for their eggs and meat in the Hawaiian Islands, and their nesting habitats destroyed, resulting in a severe population decline (Balazs 1980, Balazs \& Chaloupka 2004a). However, protection was strengthened in the late 1970s by the State of Hawaii and the US Endangered Species Act (Bennett \& Keuper-Bennett 2008), and the green turtle population has since been recovering rapidly at a rate of $5.7 \%$ per year (Balazs \& Chaloupka 2006, Chaloupka et al. 2008) over the past 35 yr.

Although green turtles nest throughout the Northwestern Hawaiian Islands, about $90 \%$ of the nesting takes place in French Frigate Shoals (Balazs 1980). 


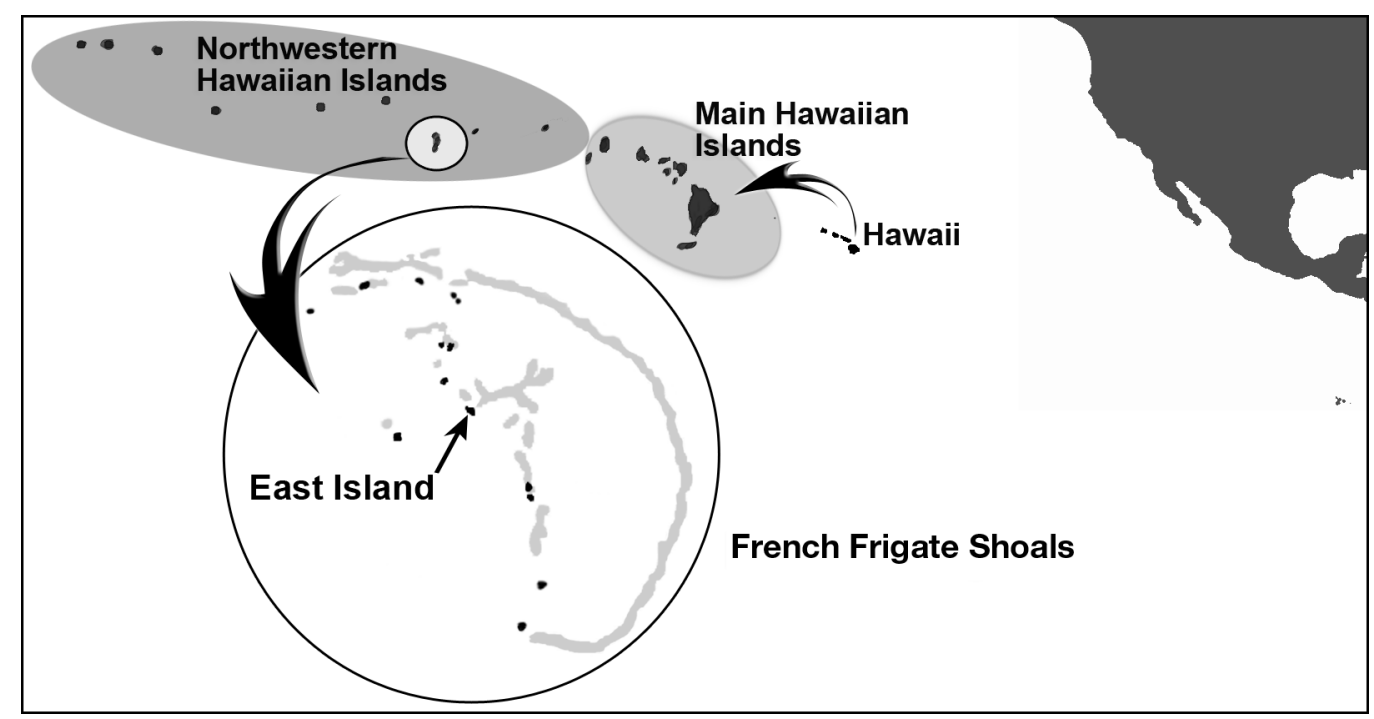

Fig. 1. Hawaiian archipelago and the location of French Frigate Shoals and East Island

Within this atoll, approximately $55 \%$ of the nesting takes place on East Island (Fig. 1), where data collection was initiated in the 1970s (Balazs 1980, Balazs \& Chaloupka 2004a). Evidence from tagging and radio telemetry work indicates that females nesting on East Island maintain strong nesting fidelity and rarely nest on any of the other islands (Balazs 1980, Dizon \& Balazs 1982). Green turtles migrate from throughout the Hawaiian archipelago to French Frigate Shoals to breed (Balazs 1976, 1980), and the numerous foraging aggregations are composed of one genetic stock and form a distinct regional population (Dutton et al. 2008). With increased nesting on East Island and decreased observations of turtles that have not been previously tagged, it has been suggested that the population may be approaching carrying capacity in the coastal foraging habitats (Balazs \& Chaloupka 2004a, Chaloupka \& Balazs 2007). However, the carrying capacity of the finite beaches of French Frigate Shoals remains to be determined.

Furthermore, loss of nesting habitat from climate change-related sea level rise has been predicted for many beaches worldwide (Fish et al. 2005, Baker et al. 2006, Fuentes et al. 2010). In the Northwestern Hawaiian Islands, sea level rise due to climate change and the natural subsidence of the northwestern segment of the archipelago over geologic time are of growing concern. Baker et al. (2006) estimated a loss in terrestrial habitat between 3 to $75 \%$ under various scenarios of sea level rise. Models predicted that, of the islands evaluated within French Frigate Shoals, East Island would persist the longest (Baker et al. 2006), suggesting that East Island may play an even greater role for green turtle nesting in the Hawaiian Islands.
Increased nesting densities on East Island would result in density-dependent changes in the nesting environment (Honarvar et al. 2008) and in densitydependent factors such as nest destruction by nesting females and disease regulating population size. Females have been observed to destroy incubating nests during their nesting process on East Island (Balazs 1980). When a turtle crawls up a beach to nest, she clears the sand around her with her flippers creating a body pit, and then excavates the nest chamber, deposits her eggs, and covers up and camouflages the nest; at high nest densities nearby incubating nests are often destroyed by a nesting turtle (Girondot et al. 2002, Caut et al. 2006, Tiwari et al. 2006). As destroyed eggs accumulate in the sand, increased microbial activity may increase mortality within incubating nests (Cornelius et al. 1991, Marcovaldi et al. 1999, Phillott \& Parmenter 2001). Density-dependent predation on nests (Tiwari et al. 2006) would not apply to East Island because of the absence of predators (Balazs 1980).

Thus, the objective of the present study is to determine the carrying capacity of East Island for hatchlings and nesting females under current conditions and the predictions of reduced nesting habitat due to sea level rise; carrying capacity is defined as the maximum number of hatchlings that can be produced in a season (Tiwari et al. 2006). Given the relatively rapid increase in the nesting population and its distinct genetic and ecological importance, evaluating the carrying capacity of key habitats and understanding ecological processes, under current scenarios and the predictions of climate change, are critical for updating and achieving recovery goals for this species (National Marine Fisheries Service and US Fish and Wildlife Service 1998). 


\section{MATERIALS AND METHODS}

French Frigate Shoals is a $35 \mathrm{~km}$ long crescentshaped atoll consisting originally of 11 islands (Amerson 1971) and currently of 8 emergent islands and 2 volcanic outcrops. Islands within the atoll differ in substrate, and East Island is characterized by a calcareous substrate composed of coarse to fine fragments of coral, coralline algae, mollusks, humus, and barnacles (Balazs 1980, Mortimer 1990). Green turtle nesting extends from May to September (Balazs 1980), and annual surveys of nesting females have been conducted on East Island since 1973. For most of these 37 seasons, night surveys have been conducted for a few weeks during the peak nesting months to count and tag turtles. Saturation surveys were conducted from 1988 to 1992, during which time the entire nesting season was monitored (Wetherall et al. 1998). Recent analyses of population trends for 30 and 32 yr of nesting have been presented by Balazs \& Chaloupka (2004a) and (2006), respectively. Here we add nesting female estimates for the years 2005 to 2009, and present an updated graphical overview of the nesting trend for the past $37 \mathrm{yr}$.

Carrying capacity at East Island was determined by using the simulation model described by Tiwari et al. (2006) to estimate carrying capacity at the green turtle nesting beach in Tortuguero, Costa Rica. The model was modified to simulate processes that affect hatchling emergence on East Island. Given the remoteness of French Frigate Shoals and the difficulties of extensive monitoring and data collection, including potential conflicts with the critically endangered Hawaiian monk seal Monachus schauinslandi, limited data are available to estimate East Island model parameters. Several life history parameters are estimated from in-depth studies on East Island during the 1970s (Balazs 1980).

In the present simulation model, all available area on the island was considered suitable for nesting, as turtles have been observed to scatter their nests randomly throughout the island (G. H. Balazs unpubl. data). The available nesting area of $30865 \mathrm{~m}^{2}$ was determined by taking the average of the mean low water line and the spring high tide as estimated by Baker et al. (2006) for East Island and subtracting the unsuitable nesting habitat, which consists of a permanent wooden platform $\left(7.5 \mathrm{~m}^{2}\right)$ and a rock pile $\left(27.1 \mathrm{~m}^{2}\right)$. The number of nests present on the beach on each day $(t)$ can be summarized by the equation:

$$
\text { Nests }_{t}=\operatorname{Nests}_{(t-1)}-F_{t}+N_{t}-H_{t}
$$

On each day $(t)$ for $174 \mathrm{~d}$, the model simulated a random value (according to the descriptions given below) for the number of nests completely destroyed by nesting females $(F)$, the number of nests deposited each day $(N)$, and the number of nests hatched $(H)$. Erosion was considered to be negligible in this model as it occurs towards the end of the season, and only at one end of East Island; this would result in lowering hatchling output and its significance would depend on the timing and intensity of the erosion. No mammalian nest predators are present on East Island, and although 2 species of ghost crabs (Ocypode ceratophthalmus and $O$. laevis) are found on the island, neither has been observed depredating incubating eggs (Balazs 1980).

Only nesting in the main months (15 May to 31 August) was considered in the model, but the model was run until early November ( $t=174 \mathrm{~d}$ ) to allow all nests laid in August to complete their average incubation period of $65 \mathrm{~d}$, which was estimated by Balazs (1980) and is similar to the mean incubation duration of 66 d estimated on Tern Island in French Frigate Shoals (Niethammer et al. 1997). The number of nests laid each day $(N)$ was drawn from a Poisson distribution whose mean was the product of the total number of nests laid in the season and the mean proportion of nests laid on that day, which was determined from the average proportion of nests laid on each day between 1988 and 1992; these were the only years for which saturation surveys were carried out. Temporal patterns of nesting appear not to have changed radically over the past 37 yr (G. H. Balazs pers. obs.). An average clutch size of 104 eggs, estimated by Balazs (1980), was assigned to each nest.

The expected probability of a nest being destroyed by a nesting female is summarized by the equation 1 $\mathrm{e}^{-A D}$, where $A$ is the area of destruction and $D$ is nest density (nests $\mathrm{m}^{-2}$ on East Island) at time of nest destruction. The area within which a female is likely to destroy another nest during her nesting process was determined from body pits excavated by nesting green turtles on East Island during the 2009 nesting season. This area on East Island measured on average $1.33 \times$ $1.5 \mathrm{~m}$, which corresponds to an area of $2.0 \mathrm{~m}^{2}$, and was assumed to be circular. Therefore, in the present study, the number of nests destroyed by each female $(F)$ on each day was drawn from a Poisson distribution with a mean defined as $2.0 \mathrm{~m}^{2} \times$ the current nest density on the beach. A female was allowed to destroy more than one nest, but the total number of nests destroyed could not exceed the total number of nests in the beach. The fraction of the nest destroyed by a nesting female varied from a few eggs to most of the eggs; a random fraction of eggs selected from a uniform distribution was subtracted from the clutch. Eggs remaining in partially destroyed nests were allowed to complete the $65 \mathrm{~d}$ of incubation and hatch (according to rules given below) and removed from the model on the day they hatched. Nests that were completely destroyed were removed from the model on the day they were destroyed. 
Hatchling output on each day $(t)$ is summarized by the equation:

$$
\text { Hatchlings }_{t}=\sum_{i=1}^{E_{t}}\left(C S \times P_{t}\right)
$$

where hatchling emergence from nests successfully completing incubation $(E)$ is determined by multiplying the number of eggs or clutch size $(C S)$ in each nest ready to hatch $(i)$ by a proportion $(P)$ randomly selected from a beta distribution with shape parameters 1.73 and 0.7 . These parameters were calculated from hatchling emergence data collected by Balazs (1980) on East Island. Nests partially destroyed by nesting females were subjected to a similar random reduction of eggs because a female's disturbance of the area while nesting may increase risks for incubating nests from increased microbial activity due to broken eggs and from changes in the environmental conditions of nests (Tiwari et al. 2006). The simulation model was run from an estimate of at least 1000 nests on East Island in recent years up to 200000 nests.

Finally, to determine the sensitivity of the model to small changes in parameters, a $20 \%$ increase in mortality during incubation was integrated into the model. To incorporate projections of maximum sea level rise by Baker et al. (2006) at East Island, the model was subsequently run with a $30 \%$ reduction in available nesting area $\left(21865 \mathrm{~m}^{2}\right)$. Increasing sea levels may also increase the water table on the island, thereby drowning nests. Therefore, model output was also evaluated with a $20 \%$ increase in mortality during incubation in addition to the $30 \%$ reduction in available nesting area. These simulations were also run for nest numbers on East Island from 1000 up to 200000 nests. The R software (R Development Core Team 2009) was used to run the models.

\section{RESULTS}

Inclusion of nesting data from 2005 to 2009 demonstrated that the nesting population is continuing to grow with the greatest number of turtles over the 37 sampling seasons nesting in 2008 (Fig. 2). In the simulation model, carrying capacity was reached between 1.9 and 2.1 million hatchlings under current conditions; carrying capacity was approached when 80000 to 120000 nests were laid on the beach (Fig. 3), which represents 2.6 to 3.9 nests $\mathrm{m}^{-2}$ if nests were uniformly distributed on the beach. The number of nests destroyed by nesting females in the model was approximately 26 per 1000 nests laid on the beach, consistent with the number of nests observed being destroyed by nesting females at the peak of the season in 2008 when the maximum number of nests was laid on East Island

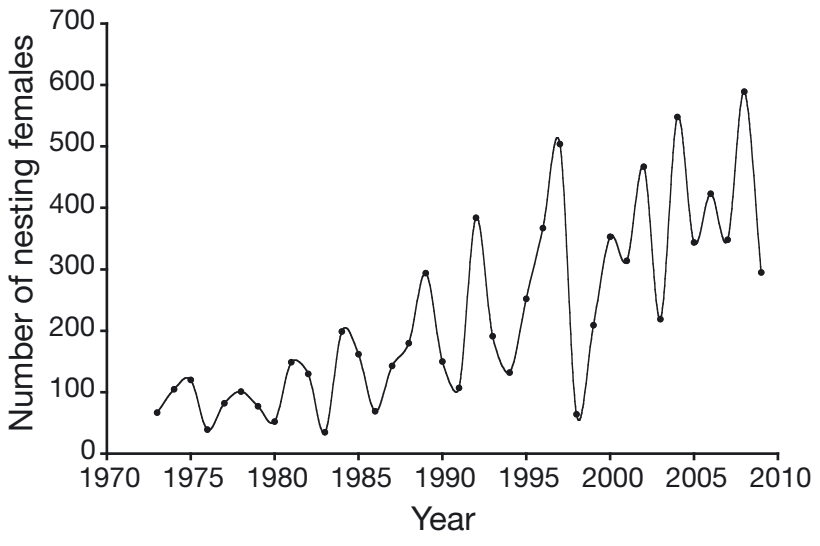

Fig. 2. Chelonia mydas. Estimated number of green turtles nesting on East Island, French Frigate Shoals, 1973-2009

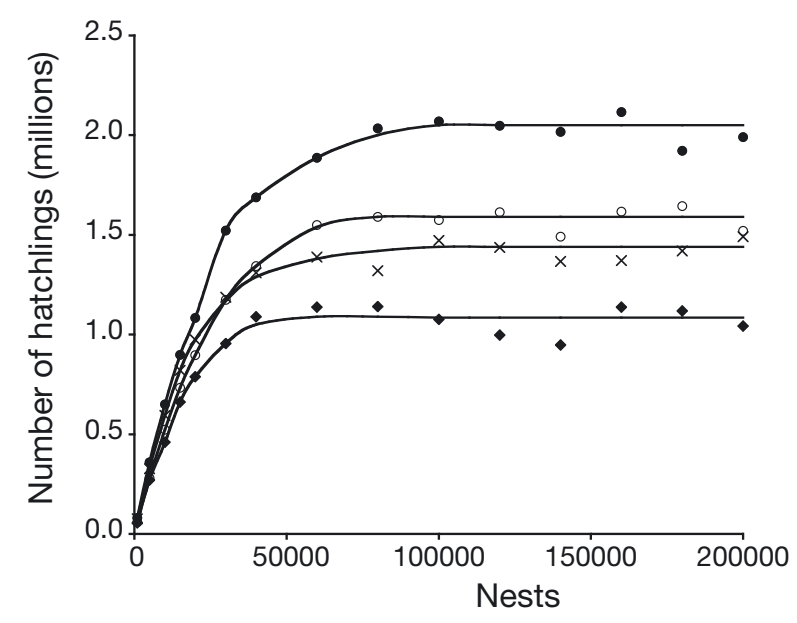

Fig. 3. Chelonia mydas. Number of hatchlings produced at East Island under different scenarios incorporated in the simulation model: current situation $(\bullet)$, current situation with $20 \%$ increase in mortality during incubation (O), sea level rise and reduced nesting habitat $(x)$, and sea level rise and reduced nesting habitat with $20 \%$ increase in mortality during incubation $(\diamond)$

(Fig. 2). For a $20 \%$ increase in mortality during incubation, hatchling output decreased and carrying capacity was reached between 1.5 and 1.6 million hatchlings; carrying capacity was approached when at least 80000 to 120000 nests were placed on the beach.

With sea level rise and a reduction in available nesting habitat, carrying capacity was between 1.3 and 1.6 million hatchlings (Fig. 3). When a 20\% increase in mortality during incubation was applied to this model, hatchling output decreased; carrying capacity was between 0.9 and 1.1 million hatchlings (Fig. 3). With a rise in sea level, carrying capacity was reached when 60000 to 100000 nests were laid on the beach. 


\section{DISCUSSION}

Although once seriously depleted due to widespread exploitation within the Hawaiian Islands (Balazs 1980), the green turtle stock in French Frigate Shoals has been making an impressive comeback. With the absence of major predators on the islands, the main factors regulating hatchling output would be intraspecific destruction of eggs, as suggested by other researchers (Bustard \& Tognetti 1969, Girondot et al. 2002, Tiwari et al. 2006, Mazaris et al. 2009), increased microbial activity resulting from a higher nutrient load after a certain nest density threshold is reached (Cornelius et al. 1991, Tiwari et al. 2006), as well as changes in the incubation environment. Honarvar et al. (2008) demonstrated experimentally that increasing the density of olive ridley Lepidochelys olivacea nests resulted in lower hatching success possibly due to higher temperatures, higher carbon dioxide levels, and lower oxygen levels. Tiwari et al. (2006) found that below-beach-surface predation, erosion, and beach flooding affected green turtle hatchling production at Tortuguero, Costa Rica, in a density-independent manner. Density-independent effects of erosion and severe tidal inundation are considered negligible during the main season on East Island; however, climate change forecasts suggest an increase in the intensity of these factors (Hawkes et al. 2009).

The beach at East Island appears to be well below its carrying capacity. If mean clutch frequency for green turtles nesting on East Island is 4 (estimated from saturation surveys during 1988-1992; G. H. Balazs unpubl. data) and the mean number of females nesting in the past $10 \mathrm{yr}$ is 390 (estimated from values in Fig. 2), then the current mean nesting population represents 1.3 to $2 \%$ of the 20000 to 30000 females that would deposit 80000 to 120000 nests on East Island at carrying capacity. Similarly, in the Caribbean, the current green turtle population is estimated to represent only 3 to $7 \%$ of pre-exploitation levels (Jackson et al. 2001). If mature females comprise $0.6 \%$ of a green turtle stock (Chaloupka \& Balazs 2007), then 20000 to 30000 females represent stocks of 3.3 to 5 million green turtles. While 20000 to 30000 females in a population falls well within acceptable estimates for some of the other large green turtle populations (Bjorndal et al. 1999, Limpus et al. 2003, Seminoff 2004) and East Island appears capable of supporting this larger nesting population, the green turtle population in French Frigate Shoals may be regulated by availability of food and refugia in suitable coastal habitats. Chaloupka \& Balazs (2007) estimated carrying capacity of the current coastal habitat to be 73600 green turtles and the current stock to be at $83 \%$ of carrying capacity. Wabnitz
(2010) also demonstrated that the green turtle foraging population at the Kaloko-Honokohau National Historical Park had reached carrying capacity. Furthermore, a decline in growth rates of immature green turtles at the foraging grounds while population abundance has been increasing suggests local density-dependent effects (Balazs \& Chaloupka 2004b). Under this scenario, East Island will successfully support increased nesting when carrying capacity is reached in the coastal habitat and if other traditional nesting areas are inundated by sea level rise. Over geological timescales sea turtles rookeries have undergone many changes resulting in colonization of new areas (Bowen et al. 1992). Nevertheless, new findings suggest that most low-lying atoll islands may either remain stable or increase in area (Webb \& Kench 2010) despite climate change-induced changes in sea level. In the end, the coastal habitats may play a bigger role in regulating the Hawaiian green turtle population than available nesting habitat.

However, the estimates of carrying capacity in the coastal habitat and the percentage of mature females present in the population (Chaloupka \& Balazs 2007) are based on limited data and inferences that have raised concerns because of their management implications (Snover 2008). Additional assessments will be necessary when more data on age and size class composition, rates of predation, and productivity of the foraging habitats become available for the Hawaiian stock. Also, impacts of climate change on the ecology and structure of key habitats, sex ratios, as well as distribution, behavior, and diet will need to be evaluated (Hawkes et al. 2009).

Given the genetic and ecological importance of the Hawaiian stock (Chaloupka \& Balazs 2007, Dutton et al. 2008), the ongoing debate on the reinstatement of indigenous hunting rights in the Hawaiian Archipelago (Chaloupka \& Balazs 2007), and the ambiguous impacts of climate change (Baker et al. 2006, Hawkes et al. 2009), an ecosystem-based assessment of the population is needed to understand the adaptability and resilience of the green turtle population within a fluctuating ecosystem. This is particularly important for devising meaningful and adaptive ecosystem-based conservation and management strategies.

Acknowledgements. This paper was greatly improved by comments from D. Kobayashi, J. Seminoff, and J. Wetherall. Our thanks go to T. Summers, I. Nurzia-Humburg and S. K. K. Murakawa for field and data assistance, and to the US Fish and Wildlife Service and the Papahanaumokuakea Marine National Monument for their help with the project. This study was conducted in accordance with institutional, national, and international guidelines concerning the sampling of endangered species. 


\section{LITERATURE CITED}

Amerson AB Jr (1971) The natural history of French Frigate Shoals, Northwestern Hawaiian Islands. Atoll Res Bull 150

Baker JD, Littnan CL, Johnston DW (2006) Potential effects of sea-level rise on the terrestrial habitats of endangered and endemic megafauna in the Northwestern Hawaiian Islands. Endang Species Res 2:21-30

Balazs GH (1976) Green turtle migrations in the Hawaiian Archipelago. Biol Conserv 9:125-140

Balazs GH (1980) Synopsis of biological data on the green turtle in the Hawaiian Islands. NOAA Tech Memo NMFSSWFC-7

Balazs GH, Chaloupka M (2004a) Thirty-year recovery trend in the once depleted Hawaiian green turtle stock. Biol Conserv 117:491-498

Balazs GH, Chaloupka M (2004b) Spatial and temporal variability in somatic growth of green sea turtles (Chelonia mydas) resident in the Hawaiian Archipelago. Mar Biol 145:1043-1059

Balazs GH, Chaloupka M (2006) Recovery trend over 32 years at the Hawaiian green turtle rookery of French Frigate Shoals. Atoll Res Bull 543:147-158

Bennett P, Keuper-Bennett U (2008) The book of Honu. University of Hawai'i Press, Honolulu, HI

Bjorndal KA, Wetherall JA, Bolten AB, Mortimer JA (1999) Twenty-six years of green turtle nesting at Tortuguero, Costa Rica: an encouraging trend. Conserv Biol 13:126-134

Bowen BW, Meylan AB, Ross JP, Limpus CJ, Balazs GH, Avise JC (1992) Global population structure and natural history of the green turtle (Chelonia mydas) in terms of matriarchal phylogeny. Evolution 46:865-881

Broderick AC, Frauenstein R, Glen F, Hays GC and others (2006) Are green turtles globally endangered? Glob Ecol Biogeogr 15:21-26

Bustard HR, Tognetti KP (1969) Green sea turtles: a discrete simulation of density-dependent population regulation. Science 163:939-941

- Caut S, Hulin V, Girondot M (2006) Impact of densitydependent nest destruction on emergence success of Guianan leatherback turtles (Dermochelys coriacea). Anim Conserv 9:189-197

Chaloupka M, Balazs GH (2007) Using Bayesian state-space modelling to assess the recovery and harvest potential of the Hawaiian green sea turtle stock. Ecol Model 205: 93-109

Chaloupka M, Bjorndal KA, Balazs GH, Bolten AB and others (2008) Encouraging outlook for recovery of a once severely exploited marine megaherbivore. Glob Ecol Biogeogr 17:297-304

Cornelius SE, Ulloa MA, Castro JC, Mata del Valle M, Robinson DC (1991) Management of olive ridley sea turtles (Lepidochelys olivacea) nesting at Playas Nancite and Ostional, Costa Rica. In: Robinson JG, Redford KH (eds) Neotropical wildlife use and conservation. The University of Chicago Press, Chicago, IL, p 111-135

Dizon AE, Balazs GH (1982) Radio telemetry of Hawaiian green turtles at their breeding colony. Mar Fish Rev 44:13-20

$>$ Dutton PH, Balazs GH, LeRoux RA, Murakawa SKK, Zarate P, Martínez LS (2008) Composition of Hawaiian green turtle foraging aggregations: mtDNA evidence for a distinct regional population. Endang Species Res 5:37-44

Fish MR, Côté IM, Gill JA, Jones AP, Renshoff S, Watkinson AR (2005) Predicting the impact of sea level rise on Caribbean sea turtle nesting habitat. Conserv Biol 19:482-491

Fuentes MMPB, Limpus CJ, Hamann M, Dawson J (2010) Potential impacts of projected sea-level rise on sea turtle rookeries. Aquat Conserv Mar Freshw Ecosyst 20:132-139

Girondot M, Tucker AD, Rivalan P, Godfrey MH, Chevalier J (2002) Density-dependent nest destruction and population fluctuations of Guianian leatherback turtles. Anim Conserv 5:75-84

Hawkes LA, Broderick AC, Godfrey MH, Godley BJ (2009) Climate change and marine turtles. Endang Species Res 7: 137-154

Honarvar S, O'Connor MP, Spotila JR (2008) Densitydependent effects on hatching success of the olive ridley turtle, Lepidochelys olivacea. Oecologia 157:221-230

Jackson JBC, Kirby MX, Berger WH, Bjorndal KA and others (2001) Historical overfishing and the recent collapse of coastal ecosystems. Science 293:629-638

Limpus C, Miller J, Parmenter C, Limpus D (2003) The green turtle, Chelonia mydas, population of Raine Island and the northern Great Barrier Reef, 1843-2001. Mem Queensl Mus 49:349-440

Marcovaldi MA, Vietas CF, Godfrey MH (1999) Nesting and conservation management of hawksbill turtles (Eretmochelys imbricata) in northern Bahia, Brazil. Chelonian Conserv Biol 3:301-307

> Mazaris AD, Matsinos G, Pantis JD (2009) Evaluating the impacts of coastal squeeze on sea turtle nesting. Ocean Coast Manage 52:139-145

Mortimer JA (1990) The influence of beach sand characteristics on the nesting behavior and clutch survival of green turtles (Chelonia mydas). Copeia 1990(3):802-817

National Marine Fisheries Service (NMFS) and U.S. Fish and Wildlife Service (1998). Recovery plan for US Pacific populations of the green turtle (Chelonia mydas). NMFS, Silver Spring, MD

Niethammer KR, Balazs GH, Hatfield JS, Nakai GL, Megyesi JL (1997) Reproductive biology of the green turtle (Chelonia mydas) at Tern Island, French Frigate Shoals, Hawaii. Pac Sci 51:36-47

Phillott AD, Parmenter CJ (2001) The distribution of failed eggs and the appearance of fungi in artificial nests of green (Chelonia mydas) and loggerhead (Caretta caretta) sea turtles. Aust J Zool 49:713-718

R Development Core Team (2009) R: a language and environment for statistical computing. R Foundation for Statistical Computing, Vienna, available at www.r-project.org

Seminoff JA (2004) 2004 Global status assessment: green turtle (Chelonia mydas). IUCN Mar Turtle Specialist Group Rev

- Snover ML (2008) Comments on 'Using Bayesian state-space modelling to assess the recovery and harvest potential of the Hawaiian green sea turtle stock'. Ecol Model 212:545-549

Tiwari M, Bjorndal KA, Bolten AB, Bolker BM (2006) Evaluation of density-dependent processes and green turtle Chelonia mydas hatchling production at Tortuguero, Costa Rica. Mar Ecol Prog Ser 326:283-293

Troëng S, Rankin E (2005) Long-term conservation efforts contribute to positive green turtle Chelonia mydas nesting trend at Tortuguero, Costa Rica. Biol Conserv 121:111-116

Wabnitz CCC (2010) Sea turtle conservation and ecosystembased management with a focus on green turtles (Chelonia mydas) and seagrass beds. PhD dissertation, University of British Columbia, Vancouver

Webb AP, Kench PS (2010) The dynamic response of reef islands to sea level rise: evidence from multi-decadal analysis of island change in the Central Pacific. Global Planet Change 72:234-246

Wetherall JA, Balazs GH, Yong MYY (1998) Statistical methods for green turtle nesting surveys in the Hawaiian Islands. In: Epperly SP, Braun J (comps) Proc 17th Annu Sea Turtle Symp. NOAA Tech Memo NMFS-SEFSC-415, p 278-280 